\section{GMO Roundup}

- Anarchists have a great new way to promote homegrown seeds. The thoroughly brave souls at Natural Reality, presumably working from a P4 facility, exposed themselves to the dangers of GM plants to produce packets of seeds labeled "SuperWeed Kit 1.0." (http://pages.hotbot.com/politics/superweed/kit.html). Apparently, these contain "a mixture of naturally occurring genetically mutated (GM) Brassica seeds" that, after germination and cross-pollination, will produce a superweed resistant to current herbicides. How purchasers can be sure about the GM varieties is not clear (although perhaps Genetic ID offers free tests to registered anarchists). Nor is it stated what the chances of producing the SuperWeed actually are; not very high, one imagines, or Natural Reality could sell SuperWeed seeds, rather than those of the "parental" lines. Natural Reality urges its adherents to pressure the authorities by threatening to release SuperWeed 1.0 into the environment. Alternatively, purchasers can "create your own propaganda campaign threatening biotech corporate interests ..." So, boys and girls, put the SuperWeed kit next to your X-ray vision glasses and your ex-KGB keyhole cameraand don't forget the secret club password.

- A background document presented to the US Environmental Protection Agency (EPA; Washington, DC) Science Advisory Panel from Environmental Defense (ED, formerly the Environmental Defense Fund; New York) at the end of February (http://www.edf.org/pubs/Filings/cry9c.html) argues that EPA should not approve Aventis' request to expand the use of corn containing the Cry9C protein to human food. ED says Aventis has not proved that Cry9C is not immunogenic and suggests that, if approved, food should be labeled to indicate potential allergenicity. Aventis officials point out that EPA's report on the product states that, "A search for amino acid homology did not reveal any significant homology with known toxins or allergens" and concludes that "no mammalian toxicity is anticipated from dietary exposure to the genetic material necessary for the production of the Cry9C protein."

Business and Regulatory News Briefs written by Emma Dorey, Alan Dove, Jeff Fox, Julie Grisham, John Hodgson, Sabine Louet, Asako Saegusa, Robert Schehr and Keely Savoie.

\title{
Pigs cloned for first time
}

PPL Therapeutics (Edinburgh, UK), the company that, along with the Roslin Institute, cloned Dolly the sheep, announced on March 14 that it had created the first pigs cloned from adult cells. Independent DNA testing of blood from the five female pigletsMillie, Christa, Alexis, Carrel, and Dotcom-confirmed that their DNA was identical to that of the cells used to produce them and different from that of the surrogate mother. PPL says the suc-

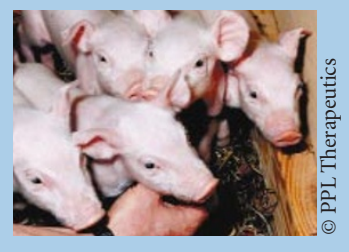
cessful cloning of the pigs opens the door to producing modified pigs whose organs and cells can be transplanted into humans. The method used to produce the piglets differs from that used to create Dolly, and the company has applied for a patent for "additional inventive steps". PPL says the next stage is to create "knock-out" pigs, in which the gene for $\alpha-1-3$ gal transferase is inactivated. That gene is responsible for the sugar group in pig cells that is recognized by the human immune system as foreign, thus causing transplant rejection. PPL says it hopes to begin clinical trials for xenotransplantation of pig organs in as little as four years.

JG

\section{Human genome bombshell}

On March 14, US President Bill Clinton and UK Prime Minister Tony Blair released a joint statement exhorting industry to make public "raw, fundamental data on the human genome, including the human DNA sequence." Confusing White House statements and mistaken reporting led to the belief that new gene patent rules were at hand. In an afternoon briefing, Francis Collins, director of the human genome project, said the statement did not intend any change in patenting rules. But he did say that "from the NIH perspective" data from cDNA libraries was considered "raw" data to be made public, thus perhaps implying DNA microarrays—which can yield the same sort of data-would also be affected. However, a later clarification excluded data from microarrays. The day's events lead to a dramatic drop in biotech stocks, with genomics companies hardest hit: Share price of Incyte Pharmaceuticals fell \$53 $(27 \%)$ to close the day at $\$ 143.5$, while Millennium Pharmaceuticals dropped 25\% to $\$ 176$, Celera $21 \%$ to $\$ 149.25$, and Affymetrix $14.4 \%$ to $\$ 203$.

The US-UK statement came one week after leaders of the not-for-profit, public-private consortium of the US National Institutes of Health (NIH; Bethesda, MD) and the Wellcome Trust (London) declared they were at loggerheads with Craig Venter, president of Celera, whose for-profit genome sequencing enterprise is following different strategies for completing sequencing and distributing its findings. The two parties had flirted with cooperating to pool their data, but talks collapsed when the consortium released a private letter outlining the difficulties in negotiating with Celera, which subsequently publicly accused the consortium of using pressure tactics. However, this left human genome matters much as they were, with the consortium promising to distribute all its sequence data rapidly and freely to the entire scientific community, and Celera planning to charge subscriber fees to some market segments and insisting on blocking potential competitors from reselling data that it considers proprietary.

Celera responsed to Clinton and Blair's statement, saying its "own mission is completely consistent with the goals of assuring that the world's researchers have access to this important information." RS\&JF

\section{Drosophila sequence "done"}

At the annual meeting of the American Association for the Advancement of Science in February, researchers presented results that provide some validation of the "shotgun" genome-sequencing approach being pursued by Celera (Rockville, MD). Collaborating with scientists in the Berkeley Drosophila Genome Project (Berkeley, CA) and the European Drosophila Genome Project, Celera successfully sequenced 97\% of the genome of the fruit fly Drosophila melanogaster, a key model organism in genetics research. The sequence covers approximately 13,000 genes, half of which have unknown functions. The shotgun method, which involves sequencing random overlapping segments of an organism's genome and then using a computer to place the segments in their proper order, is faster than the "clone-by-clone" stepwise approach being pursued by the government-funded Human Genome Project, but critics had predicted that the shotgun approach would be unworkable on the complex genomes of multicellular organisms. Indeed, the Drosophila sequence obtained by Celera still contains about 1,600 gaps, but researchers working on the project hope to fill in the missing pieces in the coming months. $A D$ 